\title{
Organización familiar durante el confinamiento en familias mexicanas*
}

\author{
Cómo citar este artículo: \\ Valle, M. E., Obregón, J. P. y Torres, L. E. \\ (2021). Organización familiar durante el \\ confinamiento en familias mexicanas. Revista \\ Latinoamericana de Estudios de Familia, \\ 13(2), 120-139. https://doi.org/10.17151/ \\ rlef.2021.13.2.7
}

\author{
María Esther Valle-Morfín** \\ Jessica Paola Obregón-Patiño**** \\ Laura Evelia Torres-Velázquez ${ }^{* * * *}$
}

Recibido: 29 de octubre de 2020 Aprobado: 30 de marzo de 2021

\begin{abstract}
Resumen: Objetivo. Analizar el trabajo doméstico en familias mexicanas durante el confinamiento por Covid-19, específicamente en las actividades de limpieza, alimentación, escolares y de ocio. Metodología. El enfoque fue cualitativo con perspectiva de género desde el construccionismo social. Participaron tres madres de familia a quienes se les realizaron entrevistas semiestructuradas. Resultados y conclusión. Se encontró que en este periodo de confinamiento las madres de familia experimentan una sobrecarga de actividades de cuidado en la organización familiar, la cual se asume y se justifica por la condición de género. No obstante, ellas están involucrando a sus familias en algunas de las actividades domésticas. Se concluyó que es necesaria la desconstrucción de los estereotipos de género que se han legitimado en las dinámicas familiares; y se reconozca a la familia extensa, entre otras personas, como una red de apoyo desde la cual las mujeres buscan construir lazos de bienestar.
\end{abstract}

Palabras clave: familia, género, trabajo doméstico, tiempo libre, actividades escolares, Covid-19.

\footnotetext{
* La presente investigación forma parte de la línea de investigación Análisis de la Dinámica Familiar, de la Unidad de Investigación Interdisciplinaria en Ciencias de la Salud y Educación de la Facultad de Estudios Superiores Iztacala, UNAM, cuyo objetivo es identificar diferentes elementos de las relaciones familiares que se puedan relacionar con el bienestar psicológico de sus integrantes o bien que pueden ser factores de riesgo ante diferentes conductas problemáticas.

** Universidad Nacional Autónoma de México. Tlanepantla, Estado de México, México.

E-mail: esthervallemorfin@comunidad.unam.mx. (iD orcid.org/oooo-0002-4082-0623. Google Scholar

*** Universidad Nacional Autónoma de México. Coyoacán, Estado de México, México.

E-mail: obrepat82@yahoo.com.mx. (iD) orcid.org/oooo-ooo2-8437-5656. Google Scholar

**** Universidad Nacional Autónoma de México. Tlanepantla, Estado de México, México.

E-mail: lauratv@unam.mx. (iD orcid.org/00oo-0002-8258-0920. Google Scholar
}

DOI: 10.17151/rlef.2021.13.2.7. 


\title{
Family organization during confinement in Mexican families
}

\begin{abstract}
Objective. To analyze domestic housework in Mexican families during Covid-19 confinement, specifically in cleaning, feeding, school work and leisure activities. Methodology.

The approach was qualitative with a gender perspective from social constructionism. Three mothers participated to whom semi-structured interviews were applied. Results and conclusion. One of the findings was that in this period of confinement, mothers experienced overloading of caring activities in the family organization, which is assumed and justified by gender. However, they were involving their family in housework duties. It was concluded that deconstruction of gender stereotypes, that have been legitimized in family dynamics, is necessary and that extended family, among other people, are recognized as a support network from which women seek to build bonds of well-being.
\end{abstract}

Key words: family, gender, housework, leisure, school work, Covid-19.

\section{Introducción}

La Organización Mundial de la Salud (OMS) declaró al Covid-19 como pandemia el 11 de marzo de 2020, ya que la enfermedad se había extendido a nivel internacional ocasionando afectaciones de salud a una gran cantidad de personas (Centro de Coordinación de Alertas y Emergencias Sanitarias, 2020; Organización Panamericana de la Salud -OPS—, 2020). Debido a esta situación, los gobiernos a nivel global comenzaron a seguir los lineamientos de la OMS, los cuales enfatizan el distanciamiento social como una medida sanitaria para retrasar la transmisión y evitar la propagación del virus (Tizón, 2020; World Health Organization, 2020). En México las actividades de desmovilización social comenzaron a partir de la segunda semana de marzo (Pantoja, 2020), donde el gobierno de la Ciudad de México en conjunto con la Secretaría de Salud implementó la estrategia de Sana Distancia, la cual consistió en la suspensión de actividades sociales no esenciales en las esferas públicas y privadas, así como el resguardo en casa (Secretaría de Salud, 2020).

Bajo este panorama, la familia cobró aún más importancia ya que no solo era la institución encargada de la construcción integral del ser humano por medio del establecimiento de vínculos emocionales, creación de hábitos de responsabilidad y bienestar acordes con los roles sociales, así como reconocimiento de la autoridad 
(Berger y Luckmann, 1986; Oliva y Villa, 2014), sino que ahora se enfrentaba con el desarrollo de las prácticas cotidianas, que anteriormente se llevaban a cabo en escenarios públicos (tales como las instituciones educativas y de trabajo) y que comenzaron a realizarse en casa, lo cual representó un cambio importante dentro de la organización familiar.

Es importante mencionar que las prácticas que se están llevando a cabo dentro del espacio familiar son permeadas por la condición de género, marcando un límite entre aquellas que son permitidas y las que se conciben fuera de la norma (Serret, 2008). En este sentido, existen expectativas que se relacionan con el rol que tiene cada miembro de la familia, ya que estas fungen como guía para el tipo de actividad que se lleva a cabo, naturalizando la diferenciación de la actividad, la cual ha sido construida bajo discursos de una división artificial del mundo, basada en ideas preconcebidas sobre lo masculino y lo femenino (Lamas, 1996; Segura, 2015).

Durante el periodo de confinamiento, la condición de género sigue presente en las prácticas cotidianas, y más aún cuando todas las actividades se han concentrado en el hogar, el cual ha sido legitimado como un espacio donde las mujeres realizan el cuidado, la alimentación y la educación informal (Seidler, 2000; Martín, 2014). En este punto es importante visibilizar cómo las familias están llevando a cabo su organización en cuanto al trabajo doméstico, trabajo no remunerado que ha recaído principalmente en las mujeres.

Entendiendo que el trabajo doméstico incluye actividades de cuidado, alimentación, limpieza de espacios, limpieza de ropa, actividades recreativas, de esparcimiento, ayuda en las tareas escolares, compra de material solicitado por las escuelas; a las que ahora en el confinamiento se han sumado actividades que antes correspondían a otros escenarios sociales, tales como la escuela, el trabajo y sitios públicos donde podían pasar parte de su tiempo libre. Por ello, el objetivo del presente trabajo es analizar el trabajo doméstico en familias mexicanas durante el confinamiento por Covid-19, específicamente en las actividades de limpieza y alimentación, actividades escolares y actividades en el tiempo libre.

\section{Metodología}

Si bien la presente investigación forma parte de la línea de investigación Análisis de la Dinámica Familiar, cuyo objetivo es identificar y analizar diferentes elementos de las relaciones familiares que se puedan relacionar con el bienestar psicológico de sus integrantes o bien que pueden ser factores de riesgo ante diferentes conductas problemáticas, para el estudio aquí reportado se diseñó como instrumento una entrevista semiestructurada y se seleccionaron a las participantes de acuerdo al objetivo de esta investigación. 
El trabajo aquí reportado es de corte cualitativo, ya que permite conocer la interconexión y la interacción entre los diferentes componentes de la investigación, lo cual favorece una comprensión de los fenómenos sociales de forma holística (Maxwell, 2013). Bajo esta lógica, el marco de referencia conceptual es el construccionismo social, ya que valora la voz de los propios participantes para dar cuenta de sus diversas realidades subjetivas, las cuales brindan sentido a sus experiencias, significados, y descripciones de la vida cotidiana desde un contexto histórico sociocultural (Donoso, 2004; Pérez, 2005; Maxwell, 2013). Para la recolección de datos se utilizó la entrevista ya que permite obtener descripciones de la realidad desde la perspectiva del participante, rescatando sus experiencias y significados (Kvale, 2011).

$\mathrm{El}$ acercamiento con las participantes fue posible gracias a las relaciones de confianza que tenían previamente con las autoras del estudio; lo cual contribuyó a que las participantes se sintieran en un ambiente de libertad y respeto. En el primer contacto, vía telefónica, se les invitó a participar, explicando el propósito de la entrevista, el principio de confidencialidad, así como la importancia de sus discursos. Una vez que aceptaron participar, se acordó la fecha y hora para llevar a cabo las entrevistas vía telefónica.

Debido a que desde el primer contacto con las participantes se planteó su privacidad, ellas decidieron cambiar sus nombres, así como el de los integrantes de su familia. Se solicitó permiso para grabar las entrevistas, a lo cual aceptaron las tres participantes. Al finalizar se agradeció su participación y confianza.

Las entrevistas tuvieron una duración aproximada de una hora y 40 minutos cada una; posteriormente se transcribieron y con base en los discursos recabados se analizaron en tres categorías: actividades de limpieza y alimentación, actividades escolares y actividades de tiempo libre.

A continuación, se describe a cada una de las participantes, que cumplieron con los criterios de ser mujeres, amas de casa y querer participar en el estudio. Cabe señalar que las participantes no fueron elegidas por su importancia numérica, sino como representantes de un orden social establecido, sustentado en los estereotipos de género, en el que se considera que las mujeres, como amas de casa, son las encargadas de la organización familiar:

Diana: tiene 48 años edad, estudió una licenciatura en trabajo social, actualmente labora en actividades de jardinería y en actividades de cuidado de un estudio de pintura. Su esposo Luis tiene 40 años, con educación básica (secundaria) y actualmente trabaja como chofer particular. Lorena es la hija mayor y tiene 10 años, cursa quinto año de primaria; su hermano Elías tiene 6 años y está cursando el primer año de primaria. Ambos se encuentran dentro de la educación básica y asisten a una escuela pública. La familia vive en la zona sur de la Ciudad de México.

Yolanda: tiene 37 años edad, estudió la licenciatura en contaduría, actualmente se dedica al hogar. Su esposo Raúl tiene 38 años, estudió una licenciatura en derecho 
y actualmente trabaja en una empresa como abogado. Daniela es la hija mayor y tiene 14 años, cursa el tercer año de secundaria; la hija de en medio es María que tiene 11 años y está en el sexto año de primaria; la hija pequeña es Aylín que tiene 5 años y cursa el tercer año de kínder. Cada una de sus hijas está en una escuela privada diferente. La familia vive en la zona noroeste del Estado de México.

Lupita: tiene 29 años, estudió la licenciatura en derecho, actualmente se dedica al hogar. Su esposo Sebastián tiene 28 años, estudió una licenciatura en ingeniería automotriz. Tienen un negocio de tortillería, donde en ocasiones Lupita colabora cobrando. Su hija Sofía tiene 5 años y asiste a un kínder privado. Viven en el Estado de Michoacán en la ciudad de Uruapan. Al igual que los padres de Sebastián, los padres de Lupita viven en Apatzingán, Michoacán.

\section{Análisis de resultados}

El trabajo doméstico o no remunerado, comprende muchas actividades que normalmente han sido delegadas a las mujeres, y han sido asumidas por ellas; llegando a ser el hogar y las actividades que allí se realizan "cosa de mujeres", así es que ellas, tanto las que tienen un trabajo fuera de casa, como las que no lo tienen, se han asumido como las responsables de todas las actividades que garantizan el buen funcionamiento de la familia en el hogar. Es de notar que cualquier actividad que los varones o los hijos realizan en el hogar, lo hacen con la convicción de que están ayudando a la mujer, y ella también lo interpreta así.

Es fundamental analizar la organización familiar en tiempo de confinamiento, ahora que todos están dentro de casa. Siendo la casa el lugar en el que la mujer hacía "sus actividades" sin la presencia de su familia, y en donde sus integrantes solo estaban presentes en una parte del día, ¿cómo se organizaron?, ¿hay más o menos actividades?, ¿quiénes las realizan?, ¿qué rutinas se han mantenido?, ¿cuáles se han añadido?, ¿cuáles se han modificado?

Para llevar a cabo este análisis nos enfocaremos en tres de estas actividades: una que se ha mantenido (actividades de limpieza y alimentación), otra que se ha incorporado (actividades escolares) y otra que se ha modificado (actividades de tiempo libre).

\section{Actividades de limpieza y alimentación}

Desde la perspectiva de género, se han evidenciado los roles tradicionales impuestos por la sociedad, de hombre-proveedor y mujer-cuidadora, retirando a los varones de las obligaciones en el hogar y penalizando a las mujeres en el trabajo extradoméstico (Hernández e Ibarra, 2019). Esta postura ha dificultado la conciliación entre la vida familiar y la vida laboral de las mujeres; conciliación 
que debiera ser una labor de todos, del Estado, de la sociedad y de la familia, y no solo una responsabilidad de las mujeres, puesto que la participación equilibrada de mujeres y hombres en ambos espacios debe contar con un marco regulatorio sólido, según Hernández e Ibarra (2019). “[...] bueno... desgraciadamente el hombre tiene la ideología que... los quehaceres pues son para mujeres" (Yolanda, comunicación personal, 7 de julio de 2020).

Lagarde (2017) señala que se ha considerado que por instinto las mujeres se encargan de la procreación, la maternidad y la vida doméstica, dentro de la esfera privada; y que por instinto los varones se dedican a lo productivo, al trabajo, al pensamiento, a la política, dentro de la esfera pública. Lo cual concuerda con Heller (1980), quien señala que se justifica por los instintos la debilidad y sometimiento de las mujeres, y la disposición a dirigir, mandar y dominar en los hombres.

[...] pero regresó a trabajar y como que volvimos... bueno yo en lo
personal, volví a sentir ese como distanciamiento de... volver otra vez
a... a querer este... ser como que un papá este... capataz, un papá muy
estricto en decir: ¿hicieron esto?, ¿hicieron lo otro?... lo que antes de la
pandemia él tenía, entonces con la pandemia pues sí cambió un poco,
pero regresando volvió a lo mismo de que: ¿por qué no arreglaron aquí? y
¿por qué hicieron esto?, ¿qué estuvieron haciendo todo el día? (Yolanda)

En México el quehacer engloba el trabajo doméstico de limpieza y alimentación, y es una actividad permanente, en la que a menudo las mujeres invierten todo su tiempo en realizarla, no hay horarios, ni retribución, ni reconocimiento, pues al ser una actividad que paradójicamente "solo se ve cuando no se hace", nadie se da cuenta del trabajo que implica y no se entiende el cansancio y a veces agotamiento de las mujeres que lo realizan.

Las mujeres tanto si trabajan fuera de casa, como si no lo hacen, se siguen encargando del quehacer, y en esta época de confinamiento este tipo de trabajo se ha incrementado, pues al estar toda la familia en casa, las actividades de limpieza y alimentación se duplican. Al respecto, Flores (2020, p. 3) señala: "La cuarentena ha cambiado recientemente el mundo del trabajo formal, informal, ilícito y autónomo, pero no ha alterado en absoluto el trabajo doméstico, con una sola advertencia: ahora es triple dentro y fuera de la casa".

Nuestras entrevistadas comentan: "[...] porque mientras estoy haciendo la tarea con ella estoy haciendo de comer, estoy lavando los trastes" (Lupita, comunicación personal, 30 de junio de 2020).

La ropa, ajá, el lavar la ropa, porque... por decir la chiquita... la chiquita es la que le gusta mínimo, cuando ha estado aquí, dos veces cambiarse, sí que, porque la primera se levanta, se baña, ya, pero... ya cuando ve que ya es este... la hora de comer, dice que pues quiere estar más bonita para 
cuando su papá la vea... pero entre la ropa de la chiquita, entre el esposo que también llega y se cambia dos veces y así... pues se ha incrementado. (Yolanda)

Sin embargo, encontramos que las mujeres entrevistadas han convenido en que todos participen en la limpieza de la casa. Cuando la mujer tiene una actividad laboral fuera de casa, es más común que en la organización familiar se involucre a los hijos en el quehacer y en ocasiones también a los esposos, pero si la mujer no tiene otra actividad laboral, se supone que ella es la única encargada del quehacer, y como tal, también ella es la encargada de buscar si necesita ayuda: "Terminamos de comer e igual nos organizamos, y un día lava los trastes de la comida Luis, otro día Lorena y así nos vamos rolando" (Diana, comunicación personal, 29 de junio de 2020).

\begin{abstract}
Este... anteriormente este... pues siempre nos hemos, así como que distribuido lo que a cada uno nos toca, pero ahorita que se presentó lo de la cuarentena platicamos y dijimos que teníamos también que... todos ser un equipo y meter las manos, entonces ellas... ellas escogieron lo que cada una tenía que hacer. (Yolanda)

Me esperaba a que termináramos la tarea, almorzamos y después hacer la limpieza, porque [mi hija] ya tiene su rol y yo tengo mi rol. Yo no me meto a su cuarto, ella no se mete a mi cuarto, ella limpia su cuarto, ella tiene su escritorio, ella ordena sus juguetes; si anda con las calcetas caminando en la casa y sabe que eso no se debe hacer, ya ella solita agarra y se pone a lavar sus calcetas este... ella barre su cuarto... trapear su cuarto. (Lupita)
\end{abstract}

No obstante, las mujeres continúan asumiendo que ellas son las encargadas de tales labores, al considerar que el quehacer que realizan sus hijos es solo ayuda: "Entonces ya llegaba igual a mi casa, veía qué es lo que se tenía que hacer, lavar o quehacer, pero por lo regular siempre está un poco recogido porque mis hijos me ayudan" (Diana, comunicación personal, 29 de junio de 2020).

[...] no, él [esposo] no se mete [en el quehacer], los platos también, ella me ayuda a lavar los platos, antes era solo su platito, $y$ su vasito $y$ ahora lava todos los platos... la jarra del agua de sabor... todas las cucharas, y yo las cazuelas, y lavo los cuchillos y lo grande pues con lo que se podrá cortar. (Lupita)

Ah pues ellas me ayudan, este... a hacer sus quehaceres de la casa, a lo mejor este... distribuíamos este... distribuimos el trabajo aquí en la casa, en donde a unas les toca a la mejor limpiar el baño de arriba, a la otra el de abajo, trapear, barrer, realizar este... el... acomodar sus cosas de cada una de sus recámaras, tenerla lista... pues a la chiquita recogiendo sus juguetes. (Yolanda) 
En cuanto a los esposos, la ayuda que proporcionan está en función de que tengan tiempo, en tanto su trabajo se los permita y ellos quieran hacerlo. Los varones no consideran que el trabajo doméstico es su trabajo, y por tanto no tienen el compromiso de hacerlo, quizá porque la masculinidad se construye como la negación de la feminidad (Connell, 2000):

\begin{abstract}
[...] no ser, no actuar como las mujeres y, por tanto, no hacer labores de cuidado... tal como el trabajo doméstico: [durante la cuarentena] él hace de comer con Sofía, limpia la casa, a Sofía le preparo la masa... ella solita hace los sopitos [sopes]. (Lupita)

Mi esposo... pues como que estaba más al pendiente de nosotras, ayudaba a hacer el quehacer... este... nos ayuda en ocasiones hasta en la cocina, a preparar el desayuno, pero regresó a trabajar y como que volvimos... bueno yo en lo personal, volví a sentir ese como distanciamiento. (Yolanda)
\end{abstract}

La equidad de género hace hincapié en las inequidades en las relaciones entre hombres y mujeres. Las mujeres al asumir las funciones de cuidado no solo hacen la limpieza y alimentación de la familia, sino que también asumen las funciones de cuidado de las instituciones sociales, cuando estas no pueden o no lo hacen (Vaquiro y Stiepovich,2010). Por ejemplo, el cuidado de la salud, la atención escolar y actividades de entretenimiento en este tiempo de pandemia, además de cuidarse ella misma, siendo evidente que esta sobrecarga de trabajo trae como consecuencia efectos en su salud física y emocional (Álvarez y Gómez, 2011).

\begin{abstract}
Sí, muy cansada, un poquito enojada, irritable, mínimo porque yo trato de controlar a la mejor... porque ahorita... bueno... es muy difícil esta... ha sido muy difícil todo este proceso, porque pues antes este... yo tenía a la mejor tres, cuatro horas para mi tranquilidad y todo... pero ahorita... se escucha mucho así... como... que se pelean de repente por una cosa, por otra... hay muchos gritos este... pues yo digo son niños, pero así como que el estado de ánimo a veces de uno, en este caso yo me he cansado demasiado, bastante, yo digo ya, ya, no doy una porque siento que el trabajo es más, cuando están los niños en casa. (Yolanda)
\end{abstract}

Ahorita es así como que más estresante [risa] porque desde que amanece... Eso sí, de repente tengo que lavar los pisos, limpiar ventanas y todo y ya, luego digo: ya, me duele mi espalda, no me molesten, me voy a dormir un rato. Y ya me duermo y amanezco fresca como la lechuga. (Diana)

Cabe señalar que aun cuando ahora las entrevistadas ven que se ha incrementado su trabajo, encontramos que ante la pregunta de qué hacían antes del confinamiento, su día también estaba saturado de trabajo, como puede apreciarse en lo comentado por ellas: 
[...] preparaba a mis hijas para la escuela, les daba de desayunar; si me tocaba llevarlas a mí a la escuela, pues las repartía a cada una de ellas a su diferente escuela, si no las lleva mi esposo este... yo nada más me encargaba de llevar a la chiquita al kínder, regresaba este... pues recogía trastes, limpiaba la casa, pues ya me metía a bañar, preparaba la comida, para alistarme para ir por ellas a la escuela, después este... regresábamos, platicamos cómo les había ido en la escuela, si tenían alguna tarea pues yo les ayudaba, este... le daba de comer, nos preparamos para ir a la clases de inglés que ellas tomaban por la tarde, regresábamos a este... hacían tareas pendientes, si se les quedaban este... después de hacer sus actividades, yo me ponía a lo mejor a leer, a dibujar este... esperando a mi esposo en las tardes... luego ya por las noches este... pues ya se metían a bañar mis niñas, este... después de esto, pues ya esperábamos a mi esposo para cenar, este... llegaba mi esposo platicábamos de cómo le había ido en el trabajo, y este... y ya nos disponíamos a dormir, y ese era nuestro día. (Yolanda)

[...] pues de lunes a viernes trabajaba yo por las mañanas, mi hora de levantarme era a las 5:30, me bañaba, a las 6 desayunaba, salía de la casa porque yo entraba a trabajar a las 7:30 y salía a las 11:30. Entonces eso me daba tiempo para venir por mis hijos, recoger a mis hijos para llevarlos a la primaria porque ellos van en la tarde, entonces ya llegaba por ellos entre 11:30 ¡mentira! 12, 12:30 dependiendo el tráfico, ya llegaba yo y mi hija estaba preparada con su hermano y ya nada más nos bajábamos a la escuela... yo les dejaba todo preparado un día antes, todo, el desayuno y la comida, para que cuando ellos se levantarán desayunaran, hicieran sus actividades de escuela. (Diana)

La llevamos a la escuela, entraba como a las 8, desayunaba, se bañaba, se arreglaba este... se iba a la escuela... salía del kínder, este... como a la 1:00... 1:10, después ampliaron para que se pudiera quedar ahí, este... en la biblioteca, a jugar, a hacer sus tareas, lo que uno como padre quisiera... venía saliendo a las 2:00 de la tarde. Yo pasaba por ella, comía, estamos aquí en la casa, cerramos el negocio como a las 5:30, llegaba, comía así... recogía lo que tuviera que recoger y ya se ponía a hacer la tarea después de comer, si tenemos chance salíamos a hacer nuestros mandados o lo que tuviéramos que hacer o nuestros pendientes. [Mientras Sofía estaba en la escuela] Salía a hacer mandados con Sergio [esposo], normalmente me ponía a hacer el almuerzo, a recoger la casa, o me salía a hacer mis pendientes y después regresaba a la casa o así, para ciertos trámites de la tortillería. (Lupita)

A pesar de la influencia que la perspectiva de género ha tenido en el estudio del trabajo doméstico, encontramos que se sigue considerando a la mujer como la responsable de todas las actividades de cuidado, concepto anclado al instinto maternal con el que supuestamente ellas nacen y esta idea se va transmitiendo de generación en generación, por lo cual es necesaria la promulgación de políticas 
públicas que incidan en la equidad de género, seguir manifestando que todas las actividades productivas dependen del trabajo doméstico, de la limpieza del hogar, de la alimentación, del cuidado de menores, adultos mayores, de enfermos; porque tener quién haga gratuitamente el trabajo doméstico, permite que se puedan llevar a cabo las actividades productivas. Es tiempo de dar el valor social, económico y político que tiene el trabajo doméstico, quitando el estigma de ser un trabajo improductivo y un trabajo naturalizado para las mujeres, porque ellas nacen con las habilidades y características para hacerlo (Sen, 2000; García, 2017).

\section{Actividades escolares}

Es común que después de clases los niños realicen tareas en casa durante un tiempo en el día y después hagan otras actividades. No obstante, el hecho de que las madres hayan entrado a sustituir a las maestras por un período de tiempo prolongado no es común para la sociedad mexicana, por lo que cada familia ha buscado formas distintas de adaptarse.

Yolanda, como madre de tres hijas, tuvo que dividir el uso de los aparatos tecnológicos con sus dos hijas, mientras se enfocaba en las actividades de su hija menor:

Este... si en la computadora una tomaba, bueno las clases eran por la televisión, las clases de Secun... esas las veían por televisión, después tenían que mandar los trabajos por vía correo, que esas sí eran por computadora o utilizaban lo que era el programa classroom, el zoom o el WhatsApp, eso ya era por el celular... [...] Pues yo me quedaba con la chiquita, porque también nos manejan en el preescolar este... horario y actividades que teníamos que hacer con ella, este... mandar evidencias a la maestra por vía WhatsApp. (Yolanda)

Mientras que para la familia de Diana el cambio fue más abrumador:

Ahorita es así como que más estresante [risa] porque desde que amanece... [...] Ellos empiezan a hacer su tarea entre las 12, 1 o 2 y ya, porque les dejaron mucha tarea, al menos a Elías, y este, y con él me dedico a estar más tiempo tanto su papá como yo para este que haga sus cosas, porque es un poco más tardado lo de él. (Diana)

Para Lupita la situación del confinamiento fue vivida con estrés:

Después pasó a hacer como que: “زoye! ¿esto cuándo va a terminar?, no, ya pasó el primer mes, ya está pasando a ser más peligroso, ya el área de contagio ya se está extendiendo, ya no se puede salir, esto ya no son unas vacaciones ya en serio” ¿no?, este la niña se empezó a estresar porque en 
la escuela siempre deja mucha tarea, ella no es de tener problema con la tarea porque siempre ha sido muy, muy dedicada pues, pero ya pasó a ser muy frustrante porque ya no era su maestra la que le explicaba y se la dejaba, ya era su mamá la que no tenía paciencia, que no tenía la experiencia para explicar y tenía que explicar, entonces ya no era bonito, ya pasó a ser frustrante, ya pasó a ser frustrante, ya pasó a ser estresante, ya la niña tenía muy poca tolerancia y yo también. (Lupita)

Los arreglos familiares en las actividades de casa se complejizan y se adaptan a los requerimientos de las instituciones escolares, que demandan actividades específicas para los padres e hijos. Es en este punto cuando lo público y lo privado se desdibuja, puesto que el lugar en donde los niños hacen sus tareas es el mismo en el que sus madres y padres realizan sus labores.

Lo anterior puede llevar a una redistribución de los tiempos de las madres, sobre todo de ellas, en las actividades escolares con las domésticas. Por ejemplo, la experiencia de Lupita es clarificadora de las estrategias que tuvo que aprender para transmitir el conocimiento a su hija, de contenidos que no se le facilitaban:

Para que no se olvide lo que hago es que estoy dando dinerito, y la
dejo que pague la tienda y pongo a la tortillería con su cubrebocas y
su careta a que reciba el dinero, y los días que me toca ayudar a mí,
la pongo ahí a que reciba el dinero y le digo: “¿cuántas monedas son?
Y esto, y lo otro", vamos a la tienda y le digo: ¿qué quieres?”, ella siempre
agarra un mamut, y yo: “ ¿cuánto cuesta un mamut?". Y le doy 20 pesos,
le doy a veces 15 pesos y le digo cuanto te tiene que sobrar y empieza ya
con los deditos, para que ya vaya conociendo el costo las cosas, el valor
de las monedas o vaya conociendo pues, y cuando estamos en casa de
mis suegros la mandamos a comprar tortillas, que baje ella a comprar
tortillas y las paga y así. (Lupita)

De alguna manera Lupita ideó aprendizajes, rescatando la cotidianeidad que representa para ella el ir a comprar, por lo que la actividad a realizar, aunque proviene de una tecnología de la información, es aterrizada a una práctica diaria que está fuera de lo virtual. Como menciona Almenara (2006), el hacer comunidades virtuales, como este caso lo es la tríada profesor, madre e hijos, representa situarse en diferentes espacios, culturas, maneras de entender los problemas, por lo que no todas las madres van a tomar la misma postura o solución, como es el caso de Diana:

Por ejemplo, con Leslie le fallaban las divisiones de punto decimal. No le entendía, y por más que yo le explicaba, a mí no me entendía, ni a su papá. Entonces como tenemos contacto directo con la maestra, le envié un correo y ya le dije: maestra Leslie así y así. Y entonces la maestra por WhatsApp me mandó ejercicios para Leslie. Y entonces, hasta con colores para que Leslie entendiera, y ¿qué crees? Que nada 
más leyó el contenido y ya ¡rápido! Y dije ¡ashhh si eso era lo que yo te quería explicar! [risa] y no me entendía. Pero a lo mejor no supe explicar las cosas. (Diana)

Un aspecto relevante en estos estudios es la emoción implicada siempre en estos cambios y cómo se pone en juego al momento de reconstruir los arreglos familiares para hacerles frente. El que sean las madres quienes proporcionen los conocimientos puede traer consigo aristas que no se preveían antes.

En algunas escuelas suele haber programas de educación socioemocional que buscan la adquisición de conocimientos, además de prevenir emociones negativas, violencia, depresión, estrés, etc. (Bisquerra, 2000; Torices, 2017). No obstante, en las casas las historias pueden ser distintas en cada una de las familias.

\begin{abstract}
[...] era estar en casa encerradas, hacer tareas, presentar resultados, no salir por el virus, dice ella, y tener que estar sin ver a las personas, no ver a sus compañeritos, no salir al área de juegos, no salir a ningún lado, cuidarnos, extremar precauciones y pues ya no era bonito, porque una cosa era llegar de la escuela, descansar, disfrutar sus juguetes, salir a la semana a un lugar bonito, los fines de semana ir con sus abuelitos, pasó todo a dar un giro de 360 grados y no fue nada grato ni para ella ni para mí porque ya nos vemos con gusto, ya nos veíamos con disgusto. (Lupita)
\end{abstract}

En este fragmento se observa la frustración y la travesía que representa para la madre y la hija estar estudiando en casa. Mientras que a Diana le costaba trabajo mantener el ritmo de trabajo con su hijo:

Porque Elías conmigo era más flojo con decir mamá ya no quiero hacerlo y con ponerme su carita de pollito... [...] Decía bueno mañana lo haces, pero entonces se le fueron acumulando hojas de actividades, entonces le dije a Luis, sabes que, no, ayúdame tú con Elí porque conmigo como que ya me agarró la... la ¿cómo te diré?, pues ya mi punto débil bueno, y entonces este ya él mejor se dedicó con Elías y ya ha avanzado bastante, ¡hasta mejoró su letra! Ya lee muy bien, lee de corrido. (Diana)

Y por último Yolanda, quien logró adaptarse a la situación y transmitir su conocimiento:

No, hasta eso, gracias a Dios, todo lo que les pedían en la escuela era entendible, yo creo que los maestros también analizaban que... pues por la distancia no podían eh... exigirles otras cosas, que ellos investigaran otras cosas sin tenerlos físicamente y podérselos expresar, este... explicar. (Yolanda) 
Cada una de las familias logró una adaptación distinta al interior de su familia, lo que lleva a replantear el cuidado emocional dentro de las mismas, lo que implica esta atención sostenida y prolongada en el tiempo (Zapata, 2016), y como se ve, a veces puede ser desgastante, confusa, frustrante o positiva.

Otro punto para resaltar en estas entrevistas, en que la mayor carga de actividades escolares está realizada por las mujeres, es que sigue existiendo una feminización del cuidado que conlleva a una doble o triple carga de trabajo para las mujeres en muchos casos (Aguilar, 2019). Lo que termina por afectar las relaciones entre los miembros de la familia y agudizar las desigualdades sociales para las mujeres de dichos hogares.

\section{Actividades de tiempo libre}

El uso del tiempo libre se puede definir como el "espacio de tiempo que los miembros de la unidad doméstica dedican a actividades de distracción, recreativas y culturales" (Salazar, 1997, p. 123), lo que significa que en este periodo de tiempo no hay ninguna actividad extra a menos que sea de ocio, de lo contrario este período estaría contaminado por otras actividades (Bittman y Wacjman, 2000). Para Sánchez y Herrero (2008) es importante el tiempo libre porque favorece el bienestar, la reflexión, el crecimiento personal y el disfrute de la vida.

Antes del periodo de confinamiento, las actividades de ocio en el tiempo libre se efectuaban más en el exterior y en lugares públicos; pero debido a las restricciones por el Covid-19 se han tenido que realizar dentro de casa y con la familia, lo que ha representado una forma de organización diferente de los tiempos y de los espacios.

De acuerdo con Salazar (1997), el abordaje del tiempo libre debe considerar a la familia, porque gracias a su análisis se demuestra que la organización de las actividades no depende solamente de una decisión individual sino colectiva; asimismo, permite conocer las normas y valores del contexto de pertenencia que se toman en cuenta para realizar dichas prácticas.

Dentro de esta lógica, se puede observar que la organización del tiempo libre también está mediado y legitimado por el género, ya que es por medio de las prácticas cotidianas donde se muestra la segmentación de actividades y de espacios para poder llevarlo a cabo. Actualmente, con el confinamiento, se puede observar cómo los varones y las mujeres utilizan los espacios dentro de su casa para pasar tiempo libre.

En el caso de los varones, comenta Yolanda con respecto a su esposo Raúl (38 años) y Diana en cuanto a su esposo Luis (40 años):

\footnotetext{
Él lo manejó a lo mejor saliendo, a limpiar sus carros, o el ver aquí dentro de la casa hasta el más mínimo detalle... como que decía no esto no es aquí, esto no es allá, pero yo trataba... al principio yo me molestaba, porque decía: "si esto ya está arreglado ¿por qué lo vas a mover?, ¿por qué lo vas a arreglar otra vez?”, pero yo traté de... como que entenderlo
} 
y decir: pues es que... es su... su forma de sacar... a lo mejor la angustia, el estrés que él tiene, porque muchas veces su preocupación era de que... pues si no trabajo no... no podemos generar para comer. (Yolanda)

Luis estuvo arreglando el carro, porque... nos lo chocaron... en eso se tardó mucho, se tarda un buen tiempo desarmando, armando, lavando. Y ya después se puso a arreglar el carro por fuera... tratando de quitarle los golpes que le dieron al carro. (Diana)

Es interesante observar que ambas participantes refieren que sus esposos pasaron parte de su tiempo con los automóviles, ya sea como en el caso de Raúl que se dedicó a limpiar; o como con Luis, que se concentró en la reparación y limpieza. Lo anterior muestra la socialización de la identidad de los hombres con respecto a la posesión de un vehículo, la cual está relacionada con el poder (Rodríguez, 2015). Asimismo, se muestra también la legitimación de ser hombre y padre, en cuanto a la falta de expresión de emociones relacionada con el mandato de proveeduría, la cual es entendida como una forma de cuidado (Ochoa, 2005; Figueroa, 2015), esto se ve cuando Yolanda se explica a sí misma que el comportamiento de su esposo, de querer arreglar todo dentro de casa, es una forma de manifestar su estrés por no estar trabajando y "no generar para comer".

En este punto se expresan los malestares masculinos asociados al manifestar sus sentimientos, los cuales están permeados por la forma en que aprendieron a expresar su vida emocional (Fleiz et al., 2008, p. 389). Asimismo, en el intento de cumplir con la tarea de ser proveedores, los varones pueden manifestar sentimientos de desesperación, autocensura y de miedo al ser señalados. Y si no cumplen con esta tarea de proveeduría, puede ser que se autorrecriminen, sientan miedo, malestar, inutilidad o presión (Ramírez, 2021). En el caso del esposo de Yolanda, él busca lidiar con estas emociones haciendo actividades que le den un sentido de utilidad. ${ }^{1}$

Otro punto para considerar en los discursos de ambas participantes es que se muestra que los esposos tienen un tiempo libre a nivel individual, el cual puede ser ocupado para reflexionar sobre la situación de confinamiento y las afectaciones que conlleva en el aspecto económico, como en el caso de Raúl que es el principal proveedor económico de la familia.

Por otro lado, en el caso de ellas, su "tiempo libre" está relacionado mayormente con las actividades realizadas en conjunto con otros miembros de la familia. Lo anterior se muestra en los siguientes discursos:

\footnotetext{
Y pues ahí le van variando en la actividad que ellos quieran hacer. Dice Lorena: "Mamá: necesito que hagamos un pan”. El otro día se aventó a hacer el pan, le dije cómo lo hiciera, ahí guiándola. Lávate los huevos, la harina, la medida, todo, y ya le salió el pan. Cenamos pan que hizo mi hija. (Diana)
}

${ }^{1}$ Para más información: Jiménez, M. L. y Tena, O. (2016). Cómo seguir siendo hombre en medio de la crisis económič Centro Regional de Investigaciones Multidisciplinarias, Universidad Nacional Autónoma de México. 


\begin{abstract}
No, sí, sí se ha incrementado [el quehacer cotidiano], porque como quieren ellas hacer postres, quieren hacer pasteles, quieren este... otro tipo de desayuno, ipues sí es un trasterío!, y más cuando... aunque ellas sí lavan los trastes que ocupan este... en ocasiones no pueden ellas a lo mejor lavar algo más... más difícil de lavar, quitarle el cochambre y así. (Yolanda)
\end{abstract}

En cuanto a lo referido anteriormente, se observan dos puntos importantes: el primero de ellos es que una parte del tiempo libre de las mujeres se vive en conjunto con prácticas domésticas, en particular con las hijas. En el primer caso, se observa que el ocio en el tiempo libre ha generado mayor tiempo de cuidado por las mujeres; lo cual se observa cuando Diana comenta que fue guiando a su hija en toda la elaboración del proceso del pan, lo cual es una práctica de cuidado en forma de supervisión para que dicha actividad terminará siendo segura para su hija y con un resultado óptimo, lo cual se logró ya que la participante comentó que la familia comió el pan que realizó su hija.

El mismo punto se puede observar de forma indirecta también en el caso de Yolanda, pues sus hijas están realizando postres. Sin embargo, ella visibiliza en primer lugar que sus quehaceres han aumentado debido a esta práctica de ocio; refiere que un punto donde hubo un cambio fue en las labores de limpieza de los trastes de cocina, lo cual se incrementó porque hay acciones que sus hijas no pueden hacer, las cuales se infiere pueden ser de fuerza corporal o debido a la falta de habilidades para poder realizarlas, una de ellas es "quitarle el cochambre".

En los discursos de ambas participantes sobre sus prácticas en tiempo libre, coinciden con lo encontrado por Pérez (2015) donde el trabajo doméstico, el cuidado y el tiempo libre se llevan a cabo simultáneamente, y esto es posible porque dichas actividades se encuentran legitimadas por los estereotipos de género, donde marcan que las mujeres son las encargadas de realizarlas y con ello se genera un valor, en este caso, dentro de la familia. A su vez, esto evidencia que las mujeres con progenie se enfrentan a barreras para el disfrute de su tiempo libre y la realización de alguna actividad de ocio a nivel individual (Bittman y Wacjman, 2000).

$\mathrm{El}$ segundo punto es con respecto a los espacios legitimados de acuerdo con las prácticas de género. Se observa que, en el caso de las hijas tanto de Diana como de Yolanda, deciden realizar la elaboración de postres, lo cual se lleva a cabo en la cocina. Esto evidencia que la familia es el primer grupo donde se socializan los aprendizajes de género, y que son las prácticas de ocio dentro del tiempo libre una forma de darles sentido a los estereotipos por medio de la valía que puede otorgar la familia. A pesar de que existe una crítica con respecto a la legitimación de espacios públicos y privados según el género (Soto, 2016), aún las actividades familiares se socializan tomando como referencia estos aprendizajes, los cuales siguen vigentes en las prácticas cotidianas, tal como lo muestran nuestras participantes. 
El caso de Lupita también coincide en que las actividades realizadas en el tiempo libre son llevadas a cabo con la familia, con las diferencias de que incluyen a la familia extensa y optaron por estar al aire libre:

\begin{abstract}
[...] llevamos a la niña a Villa [Villa Mendoza]... pero a veces nosotros no podemos porque es un gasto y como está a hora y media de aquí y sí genera un gasto, entonces ahí van mis suegros: "Ahí vamos a llevar a la niña a que se distraiga, a que corte ahora cerezas". Y pues sí es un gasto, unos 500 o 700 pesos y que, para cortar cerezas, este, pues sí genera un gasto, y que ya salieron honguitos, hay que llevar a la niña a que corte hongos, y que ya salieron cerezas hay que llevar a la niña que corte cerezas y que ya salieron duraznos hay que llevar a la niña que corte duraznos, y corte manzanas, y que para que la niña crezca sano y que para que la niña nos recuerde cortando con sus abuelitos manzanas, duraznos. (Lupita)
\end{abstract}

En el discurso anterior se observa que la familia extensa también juega un papel importante dentro de la familia nuclear, en este caso, los abuelos paternos son un apoyo para la familia de Lupita para poder realizar las actividades al aire libre que le gustan a Sofía, ya que ellos consideran que estos tiempos que comparten con su nieta son una posibilidad de construir recuerdos y lazos afectivos, además de ser una forma de cuidado hacia ella. Como se sabe, el papel de los abuelos puede ayudar a construir un estado de bienestar familiar en los ámbitos de salud, económicos y psicológicos, ya que en el tiempo de convivencia se disfruta de los vínculos afectivos entre abuelos, padres y nietos pero ya sin la carga de responsabilidad, lo que ayuda a manifestar emociones de felicidad (Prato et al., 2012; Noriega y Velasco, 2013).

Ahora bien, en este periodo de confinamiento donde una de las medidas para la prevención del Covid-19 es mantener limitados los contactos con la familia extensa, se puede observar solamente en el caso de Lupita que se realizó una evaluación sobre los costos y beneficios de la salud sobre este tipo de interacciones y, al hacerlo, optaron por tener contacto con los abuelos para que convivieran con su nieta. Con esto se evidencia que la familia extensa es también una red de apoyo ante eventos sociales complejos, tal como está sucediendo en este periodo de confinamiento.

\title{
Conclusiones
}

En este estudio se revela que la familia sigue siendo un espacio importante donde se socializan aprendizajes desde la construcción de género. En este periodo de confinamiento fue posible observar cómo siguen legitimados los estereotipos de género a través de las diferentes prácticas cotidianas. Es por tanto que el objetivo fue analizar el trabajo doméstico en las familias mexicanas durante el confinamiento por Covid-19. 
Un primer elemento para resaltar es que las mujeres en esta situación de confinamiento siguen realizando la mayoría de las actividades que tienen que ver con el cuidado en sus diferentes vertientes, tales como el trabajo doméstico, las actividades escolares y la organización del tiempo libre. Se observa que las mujeres, debido a esta sobrecarga de trabajo dentro del hogar, se enfrentan en la mayoría de los casos a estar siempre involucradas en actividades para la familia, dejando de lado la posibilidad de un tiempo de disfrute para ellas. No obstante, podemos observar algunos cambios promovidos por las mismas mujeres, tales como el repartir el trabajo doméstico entre los demás integrantes de la familia, admitir que no saben o no pueden ayudar en las labores escolares a los hijos y solicitar ayuda a sus esposos o a los maestros.

Estos cambios permiten vislumbrar algunas acciones que pueden ser retomadas por las instituciones de salud, educativas y legislativas para modificar la idea de que el cuidado y el trabajo doméstico solo es labor de las mujeres, e impulsar la idea de la corresponsabilidad, puesto que, si es cuestión de salud, el médico le solicita a la madre atienda sus indicaciones y haga tal o cual procedimiento o vigile la administración de medicamentos; si es cuestión de educación, se le solicita a la madre que refuerce lo aprendido en los niños o vigile la realización o cumplimiento de las tareas. En el confinamiento también se le solicita que haga uso de su creatividad y mantenga ocupados y entretenidos a los niños, no obstante que su dinámica cambió y su trabajo dentro del hogar se incrementó.

Todo esto nos lleva a la necesidad de seguir reflexionando y haciendo propuestas para el logro de la deconstrucción de los estereotipos de género dentro de las actividades familiares, con el fin de que las políticas públicas en realidad tengan un impacto en la sociedad, para que en momentos de complejidad, como lo es en este momento, se logre tener un balance en las dinámicas y actividades familiares a través de una distribución equitativa de tareas, y con ello que las mujeres también puedan gozar de bienestar físico y emocional.

Para finalizar, si bien es cierto que en este periodo de confinamiento las cifras de violencia intrafamiliar han aumentado (Secretaría de Seguridad y Protección Ciudadana, 2021), en el caso del presente estudio las participantes no refirieron eventos de esta índole. Sin embargo, se reconoce la importancia de abordar este tema en futuras investigaciones debido al impacto que tiene la violencia en temas de salud. 


\section{Referencias}

Aguilar, L. (2019). Pensar en el cuidado como problema social. En M. Venturiello, P. Aguilar, K. Ramacciotti, F. Zorrozúa, G. Guerrero, M. Frega y A. Bottini. (Coords.). Los derroteros del cuidado. Unidad de Publicaciones del departamento de Economía y administración, Universidad Nacional de Quilmes, Departamento de Economía y Administración.

Almenara, J. (2006). Comunidades virtuales para el aprendizaje. Su utilización en la enseñanza. Edutec. Revista Electrónica de Tecnología Educativa, (20), a053-a053.

Álvarez, R. y Gómez, I. (2011). Conflicto trabajo-familia, en mujeres profesionales que trabajan en la modalidad de empleo. Pensamiento Psicológico, 9(16), 89-106.

Berger, L. y Luckmann, T. (1986). La construcción social de la realidad. Amorrortu Editores.

Bisquerra, R. (2000). Educación emocional y bienestar. Praxis.

Bittman, M. y Wacjman, J. (2000). The rush hour: The character of leisure time and gender inequity. Social Forces, 70(1), 165-189.

Centro de Coordinación de Alertas y Emergencias Sanitarias. (2 de junio de 2020). Información CientíficaTécnica. Enfermedad por Coronavirus, COVID-19. https://www.mscbs.gob.es/profesionales/ saludPublica/ccayes/alertasActual/nCov-China/documentos/ITCoronavirus.pdf

Connell, R. (2000). The Men and the Boys. University of California Press.

Donoso, T. (2004). Construccionismo social: Aplicación del grupo de discusión en praxis de equipo reflexivo en la investigación científica. Revista de Psicología de la Universidad de Chile, XIII(1), 9-20.

Figueroa, J. (2015). El ser hombre desde el cuidado de sí: Algunas reflexiones. Revista Latinoamericana de Estudios de Familia, 7, 121-138.

Fleiz, C., Ito, M., Medina-Mora, M. y Ramos, L. (2008). Los malestares masculinos: Narraciones de un grupo de varones adultos de la Ciudad de México. Salud mental, 31(5), 381-390.

Flores, J. (2020). Género, cuarentena y Covid-19: para una crítica del trabajo doméstico. Pensar la pandemia. Observatorio social del coronavirus. CLACSO.

García, B. (2017) El trabajo doméstico y de cuidado en México. Coyuntura demográfica, (11), 69-73.

Heller, A. (1980). Instinto, agresividad y carácter. Península.

Hernández, M. e Ibarra, L. (2019). Conciliación de la vida familiar y laboral. Un reto para México. Revista de Ciencias Sociales y Humanidades, (86), 159-184.

Kvale, S. (2011). Las entrevistas en investigación cualitativa. Morata.

Lagarde, M. (2017). Identidad de género y derechos humanos. La construcción de las humanas. En C. Barros y S. García (Coords.). Gênero, Meio Ambiente e Direitos Humanos (pp. 127-163). Expressão Gráfi ca e Editora.

Lamas, M. (1996). La antropología feminista y la categoría de género. En M. Lamas (Comp.). El género: la construcción cultural de la diferencia sexual. (pp. 97-125). Programa Universitario de Estudios de Género, UNAM - Miguel Ángel Porrúa.

Martín, R. B. (2014). Contexto de aprendizaje. Formales, no formales e informales. e-Rervista didáctica, 12(7), 1-14. http://hdl.handle.net/11336/102958 
Maxwell, J. (2013). Diseño de investigación cualitativa. Gedisa.

Noriega, C.y Velasco, C. (2013). Relaciones abuelos-nietos: una aproximación al rol del abuelo. Sociedad y Utopia, Revistas de Ciencias Sociales, 41, 464-482.

Ochoa, M. (2005). Paternidad e identidad masculina en Costa Rica: El sobredimensionamiento del mandato de la proveeduría. Diálogos, Revista Electrónica de Historia, 5(1-2), 1-27. https://www. redalyc.org/comocitar.oa?id=43926968020

Oliva, E. y Villa, V. (2014). Hacia un concepto interdisciplinario de la familia en la globalización. Justicia Juris, 10(1), 11-20.

Organización Panamericana de la Salud -OPS—. (2020). La OMS caracteriza al COVID-19 como una epidemia. https://www.paho.org/hq/index.php?option=com_content\&view=article\&id $=1575$ 6: who-characterizes-covid-19-as-a-pandemic\&Itemid=1926\&lang=es

Pantoja, C. (2020). Modelos epidemiológicos e inteligencia epidemiológica. Boletín sobre COVID-19. Salud pública y Epidemiología, 1(4), 3-6.

Pérez, S. (2015). El trabajo: entre los cuidados, el tiempo libre y la problemática de la igualdad de género. En C. Prieto (Coord.). Trabajo, cuidados, tiempo libre y relaciones de género en la sociedad española (pp. 87-108). Editorial Cinca.

Pérez,T. (2005). La perspectiva constructivista en la investigación social. Revista Tendencias y Retos, (10), 39-64.

Prato, A., Hernández, A., Techera, L. y Rivas, R. (2012). Abuelos y nietos ¿una relación necesaria? Biomedicina, 7(2), 22-36.

Ramírez, J. C. (2021). Mandatos de la masculinidad y emociones: hombres (des)empleados. Página Seis.

Rodríguez, R. (2015). Juegos de chicos, lesiones de jóvenes, muertes de hombres: masculinidades y prevención de la violencia. Sociológica, 30(84), 75-115.

Salazar, C. (1997). El uso del tiempo libre y las relaciones asimétricas de género y entre generaciones. Sociológica, 12(33), 119-137.

Sánchez, S. y Herrero, A. (2008). La importancia de la perspectiva de género en la psicología del ocio. Anales de psicología, 24(1), 64-76.

Secretaría de Salud. (28 de febrero de 2020). Se confirma en México caso importado de coronavirus COVID-19. https://www.gob.mx/salud/prensa/077-se-confirma-en-mexico-caso-importado-decoronavirus-covid-19

Secretaría de Seguridad y Protección Ciudadana (2021). Información sobre violencia contra las mujeres. Incidencias delictivas y llamadas de emergencia 9-1-1. Sistema Nacional de Seguridad Pública.

Segura, R. (2015). Conceptos básicos de la perspectiva de género. En M. Dorantes y L. Torres (Comps.). Perspectiva de género en las áreas de la salud y la educación (pp. 1-27). UNAM-FES Iztacala.

Seidler, V. J. (2000). La sin razón masculina. Masculinidad y teoría social. Unam/Paidós/PUEG/CIESAS.

Sen, A. (2000). Desarrollo y libertad. Planeta.

Serret, E. (2008). Qué es y para qué es la perspectiva de género. Libro de texto para la asignatura: perspectiva de género en educación superior. Instituto de la mujer Oaxaqueña. 
Soto, P. (2016). Espacio y género: problemas, momentos y objetos. En H. Moreno y E. Alcántara (Coords.). Conceptos clave en los estudios de género, Vol. 1, (pp. 77-90). Universidad Nacional Autónoma de México - Centro de Investigaciones y Estudios de género.

Tizón, J. (2020). Salud emocional en tiempos de pandemia. Herder.

Torices, A. (2017). Educación emocional en la tutoría: una intervención psicoeducativa (reporte de experiencia profesional de Maestría). Facultad de Psicología, UNAM, México.

Vaquiro, S. y Stiepovich,J. (2010). Cuidado informal, un reto asumido por la mujer. Ciencia y Enfermería, XVI(2), 9-16.

World Health Organization. (2020). Responding to community spread of COVID-19. Interim guidance. https://apps.who.int/iris/bitstream/handle/10665/331421/WHO-COVID-19Community_Transmission-2020.1-eng.pdf?sequence=1\&isAllowed=y

Zapata, A. (2016). Madres y padres en contextos transnacionales: el cuidado desde el género y la familia. Desacatos, (52), 14-31. 